\title{
Acute Kidney Injury in Mechanically Ventilated Patients in Pediatric Intensive Care Unit in Children Hospital, Zagazig University Alaa Zidan Ibrahim ${ }^{1}$, Mohamed Abdel-Salam Gomaa ${ }^{1}$, Hanaa Hosni El-Sayed ${ }^{2}$, Omar Abdel Badeea Abdel Monem Ali" \\ Departments of ${ }^{1}$ Pediatrics and ${ }^{2}$ Clinical Pathology, Faculty of Medicine - Zagazig University. \\ *Corresponding Author: Omar Abdel Badeea Abdel Monem Ali, Mobile: +20 01226914424,
}

Email: Omar.2020.@gmail.com

\begin{abstract}
Background: Over the last decade, the nephrology and critical care communities have repeatedly shown that acute kidney injury (AKI) in children and adults portends poor short-term and long-term outcomes independent of severity of illness. Objective: This study aimed to assess the incidence of acute kidney injury in mechanically ventilated patients in pediatric intensive care unit.

Patients and Methods: This study was prospective cohort study, which conducted on 120 mechanically ventilated patients admitted to Pediatric Intensive Care Unit, Zagazig University Hospital. We described acute kidney injury by using PRIFLF criteria and Neutrophil Gelatinase Associated Lipocalin (NGAL) was measured.

Results: About $54 \%$ of patients developed AKI. Mean value of length of hospital stay (days) was significantly higher among AKI than in non-AKI. Mean value of NGAL was significantly higher between AKI and No AKI.

Conclusion: About half patients developed AKI. Creatinin was significantly higher among AKI. Urine output was significantly lower among AKI. Length of hospital stay and NGAL was significantly higher among AKI and No AKI. Keywords: Pediatric Intensive Care Unit- AKI- incidence.
\end{abstract}

\section{INTRODUCTION}

Acute kidney injury (AKI) is one of the most common conditions seen in the Pediatric Intensive Care Unit (PICU) setup. Studies show that AKI is independently associated with poor outcome. 0 by 25 , a global initiative with a strong emphasis on developing countries in Africa, Asia, aims to eliminate preventable deaths from AKI worldwide by 2025 . To achieve this ambitious goal, the mission is to call for globally applicable strategies that permit timely diagnosis and treatment of AKI for patients with potentially reversible diseases. AKI is often preventable and treatable with few, if any, long-term health consequences. However, the lack of early identification and treatment in many countries means that patients often do not receive essential care before it is too late. We need to identify people who are at risk, monitor them appropriately, diagnose the problem early, and provide reliable and consistent treatment to everyone ${ }^{(\mathbf{1})}$.

While investigators have begun to focus on AKI in the Adult Intensive Care Units, there is a paucity of data in the area of pediatric AKI, in which the population is heterogeneous at varying ages and AKI etiology is often multifactorial ${ }^{(2)}$.

The urine represents a rich, noninvasive source of potential biomarkers. This is particularly relevant in the neonatal population where blood-sparing studies are paramount to standard clinical care. To determine whether there is an association between candidate urinary biomarkers and AKI in this vulnerable population ${ }^{(3)}$.

NGAL is one of most robustly induced proteins by the kidney after experimental ischemic or nephrotoxic injury ${ }^{(4)}$.
The study aimed to assess the incidence of acute kidney injury in mechanically ventilated patients in Pediatric Intensive Care Unit and to identify risk factors for AKI.

\section{PATIENTS AND METHODS}

This study was prospective cohort study, which conducted on 120 mechanically ventilated patients admitted to Pediatric Intensive Care Unit, Zagazig University Hospital in the period from 2018 to March 2019.

Site of study: Pediatric Intensive Care Unit at Zagazig University Hospital.

Sample size and method of selection: By assuming that target population is 300 and incidence of acute kidney injury is $30 \%{ }^{(5)}$. So, the sample size was 120 using EPI-INFO program at power $80 \%$ and CI $95 \%$.

Ethical considerations: Approval from Zagazig Institational Review Board (IRP) and informed written consents were obtained from the patients participating in this study after informing them about the steps of study, the complications and the capability to withdraw at any time.

Inclusion criteria: Patients admitted to pediatric intensive care unit from age 1 month to 18 years old. Time of stay 48 hours. Mechanically ventilated patients. Exclusion criteria: Patients with previous renal disease or renal transplantation.

Data Timing: Data were collected at (Day 0,3,7) from mechanically ventilated PICU admission patients.

Study design: We described acute kidney injury by using PRIFLF criteria 
Table (1): Pediatric version of the RIFLE criteria (pRIFLE)

\begin{tabular}{|c|c|c|}
\hline Stage & eCCl \% & Urine output \\
\hline $\mathrm{R}=$ Risk for renal dysfunction & eCCl decrease by 25 & $<0.5 \mathrm{ml} / \mathrm{kg} / \mathrm{h}$ for $8 \mathrm{~h}$ \\
\hline $\mathrm{I}=$ Injury to the kidney & eCCl decrease by 50 & $<0.5 \mathrm{ml} / \mathrm{kg} / \mathrm{h}$ for $16 \mathrm{~h}$ \\
\hline $\mathrm{F}=$ Failure of kidney & $\begin{array}{l}\mathrm{eCCl} \text { decrease by } 75 \text { or } \\
<35 \mathrm{ml} / \mathrm{min} / 1.73 \mathrm{~m}^{2}\end{array}$ & $\begin{array}{l}<0.3 \mathrm{ml} / \mathrm{kg} / \mathrm{h} \text { for } 24 \mathrm{~h} \\
\text { or anuria for } 12 \mathrm{~h}\end{array}$ \\
\hline \multicolumn{3}{|l|}{$\begin{array}{l}\mathrm{L}=\text { Loss of kidney function } \\
\text { persistent failure }>4 \text { weeks }\end{array}$} \\
\hline $\begin{array}{l}E=E S R D \text { persistent } \\
\text { failure }>3 \text { months }\end{array}$ & & \\
\hline
\end{tabular}

eCCl: Estimated creatinine clearance; ESRD: End-stage renal disease; RIFLE: Risk, injury, failure, loss, end; pRIFLE: Pediatric risk, injury, failure, loss, end

Types of study: Prospective cohort study.

(A) Methods: All patients were subjected to the following:

1- Detailed History.

2- General examination (measurement of blood pressure, temperature, respiratory rate and heart rate).

3- Local examination (Chest, abdominal, cardiac and neurological examinations).

4- Investigations:

- Blood chemistry including serum urea and creatinine

- Urine output in 24 hours.

- NGAL by ELISA Kit

Storage : $2-8^{\circ} \mathrm{C}$.

Principle: This ELISA kit uses Sandwich-ELISA as the method.

\section{Statistical Analysis}

The data were coded, entered and processed on computer using SPSS (version 18). The results were represented in tabular and diagrammatic forms then interpreted. Mean, standard deviation, range, frequency, and percentage were use as descriptive statistics. ChiSquare test $\mathrm{X}^{2}$ was used to test the variables associationfor categorical data. Student's t-test was used to assess the statistical significance of the difference between two population means in a study involving independent samples. $\mathrm{P}$ value was set at $\leq 0.05$ for significant results.

\section{RESULTS}

- Table (2) showed the mean age (30.56 \pm 28.42 months) and the percentage of the females $(15.8 \%)$ and males $(84.2 \%)$.

- $\quad$ Table (3) showed the percentage of the AKI $=(54.2$ $\%)$ and No AKI $=(45.8 \%)$.

- Table (4) showed that the mean value of age, weight $(\mathrm{kg})$ and height $(\mathrm{cm}$.) were statistically significantly
- higher among AKI than No AKI. While, there was no statistically significant difference between AKI and No AKI regarding sex with higher male among No AKI. There was statistically significant difference between AKI and No AKI regarding weight $(\mathrm{kg})$ and height $(\mathrm{cm}$.) with significantly lower among No AKI.

- Table (5) showed that the mean value of length of stay (days) was statistically significantly higher among AKI than No AKI.

- Table (6) showed that there was statistically significant difference between AKI and No AKI regarding urine output (D0), urine output (D3) and urine output (D7) being significantly lower among AKI.

- Table (7) showed that there was statistically significant difference between AKI and No AKI regarding s. creatinin (D0), S.Creatinin (D3), s. creatinin (D7), bl.urea (D0), bl.urea (D3) and bl.urea (D7) being significantly lower among No AKI.

- Table (8) showed that there was statistically significant difference between AKI and No AKI regarding NGAL $(\mathrm{pg} / \mathrm{ml})$ being significantly lower among No AKI.

Table (2): Demographic data of the studied cases

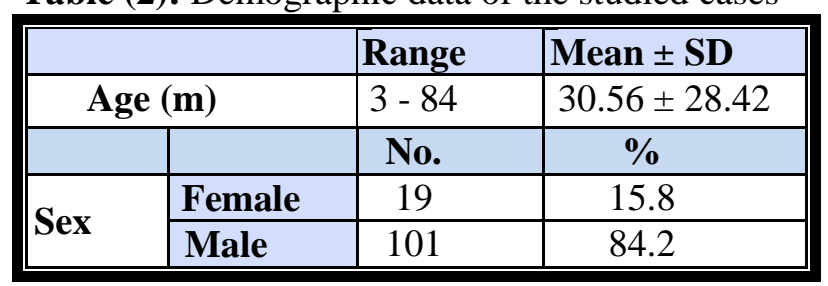

Table (3): Incidence AKI among of the studied cases

\begin{tabular}{|l|c|c|c|}
\hline \multicolumn{2}{|c|}{} & No. & $\%$ \\
\hline \multirow{2}{*}{ AKI } & AKI & 65 & 54.2 \\
\cline { 2 - 4 } & No AKI & 55 & 45.8 \\
\hline
\end{tabular}


Table (4): Comparison between cases with AKI and without AKI regarding demographic data and anthropometric measurements

\begin{tabular}{|c|c|c|c|c|c|c|}
\hline & & & $\overline{\mathrm{AKI}}$ & No AKI & t. test & P. value \\
\hline \multirow{2}{*}{ Age (m) } & \multicolumn{2}{|c|}{ Rang } & $3-84$ & $5-84$ & \multirow[t]{2}{*}{4.260} & \multirow{2}{*}{0.001} \\
\hline & Mean : & SD & $40.06 \pm 32.197$ & $19.33 \pm 17.708$ & & \\
\hline \multirow[t]{2}{*}{ Weight (kg) } & \multicolumn{2}{|c|}{ Rang } & $3-20$ & $5-15$ & \multirow[t]{2}{*}{2.347} & \multirow[t]{2}{*}{0.021} \\
\hline & \multicolumn{2}{|c|}{ Mean \pm SD } & $11.43 \pm 5.985$ & $9.39 \pm 2.611$ & & \\
\hline \multirow[t]{2}{*}{ Height (cm) } & \multicolumn{2}{|c|}{ Rang } & $52-95$ & $65-80$ & \multirow[t]{2}{*}{2.730} & \multirow[t]{2}{*}{0.007} \\
\hline & \multicolumn{2}{|c|}{ Mean \pm SD } & $78.78 \pm 18.16$ & $71.76 \pm 6.289$ & & \\
\hline \multirow{4}{*}{ Sex } & female & No. & 8 & 11 & \multirow{4}{*}{$\begin{array}{c}1.323 \\
\mathbf{X 2}\end{array}$} & \multirow{4}{*}{0.250} \\
\hline & & $\%$ & $12.3 \%$ & $20.0 \%$ & & \\
\hline & \multirow{2}{*}{ male } & No. & 57 & 44 & & \\
\hline & & $\%$ & $87.7 \%$ & $80.0 \%$ & & \\
\hline
\end{tabular}

Table (5): Comparison between cases with AKI and without AKI regarding length of stay (days)

\begin{tabular}{|c|c|c|c|c|c|}
\hline \multicolumn{2}{|c|}{ AKI } & No AKI & t. test & P. value \\
\hline $\begin{array}{c}\text { Length of stay } \\
\text { (days) }\end{array}$ & Mean \pm SD & $12.42 \pm 3.665$ & $11.42 \pm 2.432$ & 1.722 & .048 \\
\hline
\end{tabular}

Table (6): Comparison between cases with AKI and without AKI regarding urine output

\begin{tabular}{||c|c|c|l|l|l||}
\hline \multicolumn{2}{|c|}{ AKI } & No AKI & t. test & P. value \\
\hline $\begin{array}{c}\text { Urine output (D0) } \\
\text { (cc/kg/hour) }\end{array}$ & Mean \pm SD & $1.39 \pm .424$ & $1.67 \pm .174$ & $-4.571-$ & .001 \\
\hline $\begin{array}{c}\text { Urine output (D3) } \\
\text { (cc/kg/hour) }\end{array}$ & Mean \pm SD & $1.07 \pm .587$ & $1.40 \pm .172$ & $-3.974-$ & .001 \\
\hline $\begin{array}{c}\text { Urine output (D7) } \\
\text { (cc/kg/hour) }\end{array}$ & Mean \pm SD & $1.20 \pm .751$ & $1.88 \pm .180$ & $-6.402-$ & .001 \\
\hline
\end{tabular}

Table (7): Comparison between cases with AKI and without AKI regarding kidney function

\begin{tabular}{|l|l|l|l|r|r||}
\hline \multicolumn{2}{|c|}{} & \multicolumn{1}{|c|}{ AKI } & No AKI & t. test & P. value \\
\hline $\begin{array}{l}\text { S. Creatinin } \\
\text { (mg/dL) (D0) }\end{array}$ & Mean \pm SD & $1.21 \pm .054$ & $0.39 \pm .033$ & 8.763 & .001 \\
\hline $\begin{array}{l}\text { S. Creatinin } \\
\text { (mg/dL) (D3) }\end{array}$ & Mean \pm SD & $1.80 \pm 1.082$ & $0.76 \pm .183$ & 7.073 & .001 \\
\hline $\begin{array}{l}\text { S. Creatinin } \\
\text { (mg/dL) (D7) }\end{array}$ & Mean \pm SD & $1.64 \pm 1.458$ & $0.36 \pm .056$ & 6.352 & .001 \\
\hline $\begin{array}{l}\text { bl.urea } \\
\text { (mg/dL) (D0) }\end{array}$ & Mean \pm SD & $76.86 \pm 9.640$ & $23.64 \pm 4.570$ & 6.454 & .001 \\
\hline $\begin{array}{l}\text { bl.urea } \\
\text { (mg/dL) (D3) }\end{array}$ & Mean \pm SD & $91.66 \pm 7.001$ & $33.42 \pm 2.130$ & 5.844 & .001 \\
\hline $\begin{array}{l}\text { bl.urea } \\
\text { (mg/dL) (D7) }\end{array}$ & Mean \pm SD & $62.51 \pm 6.195$ & $22.75 \pm 2.738$ & 6.075 & .001 \\
\hline
\end{tabular}

Table (8): Comparison between cases with AKI and without AKI regarding NGAL

\begin{tabular}{|r|c|c|c|r|r|}
\hline \multicolumn{2}{|c|}{} & AKI & No AKI & t. test & P. value \\
\hline NGAL (pg/ml) & Mean \pm SD & $373.85 \pm 78.226$ & $266.53 \pm 69.207$ & 7.891 & .001 \\
\hline
\end{tabular}




\section{DISCUSSION}

This study showed that, there was no statistical significant difference between the studied groups regarding sex. This agrees with Paramastuty et al. ${ }^{(6)}$ who found that, there was no statistical significant difference between the studied groups regarding sex.

This study showed that $54.2 \%$ of patients developed AKI. This disagrees with Al-jboor et al. ${ }^{(7)}$ who estimated the incidence of AKI in critically ill children, of 372 patients admitted to PICU, 64 (17.2\%) patients developed AKI. The overall incidence of AKI is difficult to assess and varies among different study populations in developing countries, with an overall range from $1 \%$ to $25 \%$ in critically ill patients ${ }^{(\mathbf{8})}$. However, in other studies in critically ill patients, the development of AKI is more frequent and occurs in 15$64 \%$ of ICU patients ${ }^{(9)}$.

This study showed that mean value of weight (kg) was statistically significant higher among AKI than No AKI. This agrees with Sarafidis et al. ${ }^{(10)}$. On contrary, Hanna et al. ${ }^{(11)}$ found that infants with AKI had lower birth weight (752.2 \pm 176.6 vs. $884.1 \pm 156.6$ $\mathrm{g}, \mathrm{P}=0.02$ ).

This study showed that there was statistically significant difference between AKI and No AKI regarding s. creatinin (D0), s. creatinin (D3) and s. creatinin (D7) with significantly higher among AKI. This agrees with Kiseli et al. ${ }^{(12)}$ who reported that, mean value of creatinine was significantly higher among AKI than non-AKI.

This study showed that there was statistically significant difference between AKI and No AKI regarding urine output (D0), urine output (D3) and urine output (D7) with significantly lower among AKI. This agrees with Ghobrial et al. ${ }^{\left({ }^{(13)}\right.}$ who found that the mean urine output (UOP) was $1.9 \pm 0.6$, which, although normal, is significantly lower in cases than in controls $(2.3 \pm 0.8),(\mathrm{P}=0.043)$.

This study showed that mean value of length of hospital stay (days) was significantly higher among AKI than non-AKI (12.4 and 11.4 respectively). This agrees with Hashemian et al. (14) who found that patients with AKI had longer ICU stays $(7.6 \pm 7.6$ vs. $3.7 \pm 2.8$ days respectively. This also is in agreement with Ahmed et al. ${ }^{(15)}$ who found that AKI group had longer length of stay compared to the non-AKI group (20 vs. 12 days, $p=0.0175$ ). However, This disagrees with Paramastuty et al. ${ }^{(6)}$ who found that, length of stay of AKI group in pediatric critically ill is 17 days while non-AKI is 15 days $(\mathrm{P}=0.64)$.

This study showed that, mean value of NGAL was significantly higher between AKI and No AKI. This disagrees with Sarafidis et al. ${ }^{(\mathbf{1 0})}$ who found that, the analysis of 56 urine samples revealed that cases had significantly higher uNGAL concentrations than controls only. However, further analysis of uNGAL values gave similar results.

\section{CONCLUSION}

About half of patients developed AKI. Creatinine was significantly higher among AKI. Urine output was significantly lower among AKI. Mean value of length of hospital stay (days) was significantly longer between AKI than non-AKI. Mean value of NGAL was significantly higher between AKI and No AKI.

\section{REFERENCES}

1. Gupta S, Sengar G, Meti P et al. (2016): Acute kidney injury in Pediatric Intensive Care Unit: Incidence, risk factors, and outcome. Indian journal of critical care medicine, 20 (9): 526-529.

2. Jetton J, Askenazi D (2012): Update on acute kidney injury in the neonate. Curr Opin Pediatr., 24: 191-196

3. Heise D, Rentsch K, Braeuer A et al. (2011): Comparison of urinary neutrophil glucosaminidase-associated lipocalin, cystatin $\mathrm{C}$, and $\alpha 1$-microglobulin for early detection of acute renal injury after cardiac surgery. Eur J Cardiothorac Surg., 39: 38-43.

4. Mishra J, Ma Q, Prada A et al. (2003): Identification of neutrophil gelatinase-associated lipocalin as a novel early urinary biomarker for ischemic renal injury. J Am Soc Nephrol., 14: 2534-2543.

5. Carmody J, Swanson J, Rhone E et al. (2014): Recognition and reporting of AKI in very low birth weight infants. Clin J Am Soc Nephrol., 9 (12): 2036-43.

6. Paramastuty I, Soebandiyah K, Basuki B (2016): Urinary Kidney Injury Molecule-1 (KIM-1) in Early Diagnosis of Acute Kidney Injury in Pediatric Critically III. Journal of Tropical Life Science, 1: 28- 34

7. Al-jboor W, Almardini R, Al Bderat J et al. (2016): Acute kidney injury in critically ill child. Saudi J Kidney Dis Transpl., 27: 740-7.

8. Brochard L, Abroug F, Brenner M et al. (2010): An official ATS/ERS/ESICM/SCCM/ SRLF statement: Prevention and management of acute renal failure in the ICU patient: An international consensus conference in intensive care medicine. Am J Respir Crit Care Med., 181: 1128-55.

9. Uchino S, Kellum J, Bellomo R et al. (2005): Acute renal failure in critically ill patients: A multinational, multicenter study. JAMA., 294: 813-8.

10. Sarafidis K, Tsepkentzi E, Diamanti E et al. (2013): Urine neutrophil gelatinase-associated lipocalin to predict acute kidney injury in preterm neonates. A pilot study. Pediatric Nephrology, 29 (2): 305-310.

11. Hanna M, Askenazi D, Selewski D (2016): Drug-induced acute kidney injury in neonates. Current Opinion in Pediatrics, 28 (2): 180-187.

12. Kiseli M, Caglar G, Yilmaz H et al. (2017). Neutrophil Gelatinase-Associated Lipocalin Levels During Pneumoperitoneum. Journal of the Society of Laparoendoscopic Surgeons, 21 (1): 91-96.

13. Ghobrial E, Elhouchi S, Eltatawy S et al. (2018). Risk factors associated with acute kidney injury in newborns. Saudi J Kidney Dis Transpl., 29: 81-87.

14. Hashemian S, Jamaati H, Farzanegan B et al. (2016). Outcome of Acute Kidney Injury in Critical Care Unit, Based on AKI Network. Tanaffos., 15 (2): 89-95.

15. Ahmed M, Lim R, Selvaratnam V et al. (2012): Survival akin to injury, hospitalized patients with acute kidney injury based on the AKIN classification. Clin Nephrol., 78: 370375 . 